\title{
Sea State Bias Variability in Satellite Altimetry Data
}

\author{
Yongcun Cheng ${ }^{1,2}$, Qing Xu ${ }^{3} \mathbb{C}$, Le Gao ${ }^{4,5}$, Xiaofeng $\mathrm{Li}^{4,5, * \mathbb{C}}$, Bin Zou ${ }^{6}$ and Ting Liu ${ }^{6}$ \\ 1 College of Marine Sciences, Shanghai Ocean University, Shanghai 201306, China; yccheng.en@gmail.com \\ 2 Shenzhen AeroImgInfo Technology Co., Ltd., Shenzhen 518000, China \\ 3 College of Oceanography, Hohai University, Nanjing 210098, China; maggiexu@hhu.edu.cn \\ 4 CAS Key Laboratory of Ocean Circulation and Waves, Institute of Oceanology, Chinese Academy of Sciences, \\ Qingdao 266071, China; gaole@qdio.ac.cn \\ 5 Center for Ocean Mega-Science, Chinese Academy of Sciences, Qingdao 266071, China \\ 6 National Satellite Ocean Application Service (NSOAS), Key Laboratory of Space Ocean Remote Sensing and \\ Application, State Oceanic Administration, Beijing 100081, China; zoubin@mail.nsoas.org.cn (B.Z.); \\ liuting@mail.nsoas.org.cn (T.L.) \\ * Correspondence: lixf@qdio.ac.cn; Tel.: +86-532-82898823
}

Received: 21 March 2019; Accepted: 7 May 2019; Published: 17 May 2019

\begin{abstract}
Sea State Bias (SSB) contributes to global mean sea level variability and it needs $\mathrm{cm}$-level range adjustment due to the instrumental drift over time. To investigate its variations and correct the global and regional sea level trend precisely, we calculate the temporal and spatial variability of the SSB correction in TOPEX, Jason-1, Jason-2 and Jason-3 missions, separately, as well as in the combined missions over the period 1993-2017. The long-term trend in global mean operational 2D non-parametric SSB correction is about $-0.03 \pm 0.03 \mathrm{~mm} / \mathrm{yr}$, which accounts for $1 \%$ of current global mean sea level change rate during 1993-2016. This correction contributes to sea level change rates of $-1.27 \pm 0.21 \mathrm{~mm} / \mathrm{yr}$ and $-0.26 \pm 0.13 \mathrm{~mm} / \mathrm{yr}$ in TOPEX-A and Jason-2 missions, respectively. The global mean SSB varies up to 7-10 mm during the very strong ENSO events in 1997-1998 and 2015-2016. Furthermore, the TOPEX SSB trend, which is consistent with recently reported sea level trend drift during 1993-1998, may leak into the determined global sea level trend in the period. Moreover, the Jason-1/2 zonal SSB variability is highly correlated with the significant wave height (SWH). On zonal average, SSB correction causes about $1 \%$ uncertainty in mean sea level trend. At high SWH regions, the uncertainties grow to $2-4 \%$ near the $50^{\circ} \mathrm{N}$ and $60^{\circ} \mathrm{S}$ bands. This should be considered in the study of regional sea level variability.
\end{abstract}

Keywords: sea state bias; sea level; significant wave height

\section{Introduction}

TOPEX, Jason-1, Jason-2 and Jason-3 have provided 25-years of continuous and near-global coverage of sea level measurements. These altimeter sensors can precisely monitor sub centimeter global mean sea level change and thus obtain its rising rate [1,2]. The Sea State Bias (SSB) is one of the largest error sources for constructing the global mean sea level (GMSL) time series. The error is on the order of a few tens of centimeters and it must be properly corrected in satellite altimetry data [3,4]. For example, the GMSL rise rate changes from $1.7 \mathrm{~mm} / \mathrm{yr}$ to $2.8 \mathrm{~mm} / \mathrm{yr}$ when the new model, BM4 model [5], was updated in TOPEX data reprocessing for the period of 1993-2002 [6]. The altimeter instrumental drift may also induce an error of $0.05-0.10 \mathrm{~mm} / \mathrm{yr}$ in the GMSL rate through non-parametric SSB over the period of 1993-2008 (i.e., TOPEX and Jason-1) [7].

The SSB combines an electromagnetic bias, a skewness bias, an instrument tracker bias, and compensates the bias of the altimeter range measurement towards the troughs of ocean waves. It was originally simply modeled as a percentage of the significant wave height (SWH). Later, the combined 
SSB effect was estimated using the empirical BM4 model [5], which presents a relationship among SSB, $\mathrm{SWH}$, and wind speed at a height of $10 \mathrm{~m}\left(\mathrm{U}_{10}\right)$ or radar cross section $\sigma_{0}$ [8-13].

The theoretical modeling of the SSB is still a challenging problem, because SSB is a function of instrumental error, a wave-height-dependent bias associated with the retracking, and the ocean wind and wave conditions (e.g., fully developed swell waves and wind waves). The empirical models do not necessarily represent the actual complexity of the relationship between SSB, SWH and $\mathrm{U}_{10}$. Tran et al. [9] has pointed out that the operational SSB estimation is base on empirical models for each sensor. Sea surface height (SSH) without SSB correction is used to determine the relationship among SSB, SWH and $U_{10}$ through parametric or non-parametric methods [8,14-17]. Therefore, the uncertainties in forming SSH can leak into the SSB models and cause artificial and erroneous features in the SSB estimates [18-20]. To overcome the major drawback, several non-parametric SSB models have been developed to produce a predictor-response relationship directly from the regression data without imposition of a specific functional relation between the estimated SSB and the predictors, and the three-dimensional (3D) nonparametric models were developed using the wave period data from WAVEWATCH III [21,22] or ERA-Interim model [23] to account for the effects of wave development on altimetry sea level measurements. Recently, Passaro et al. [24] developed an SSB model to reduce the re-tracker related SSB noise by applying the ALES retracker and improve the sea level anomaly retrieval in coastal regions.

Considering the effects of SSB on GMSL trend [7], we further analyzed the spatial and temporal variability of state-of-the-art SSB models used in various altimetry missions, to show its effects on global and regional sea level trend estimation, and compared with results from several recent studies on the GMSL trend drift in TOPEX (1993-2002) missions (phases A and B) [25-27]. This work improved our understanding on the determination of GMSL trend in TOPEX and Jason-2 era.

\section{Data and Methods}

The SSB corrections in operational SSH products are 2D [15] and 3D non-parametric models [21]. RADS (Radar altimetry database system, http://rads.tudelft.nl/rads/rads.shtml) provides consistent record of sea level from multi-satellite altimetry missions, as well as the applied range and geophysical corrections. In RADS, the inter-mission biases have been corrected to provide continuous sea level record.

In this work, we analyzed over 24 years (from 1993 to 2017) of along-track data consisting of SSHA, SWH and SSB from the TOPEX-A, TOPEX-B (started on February 10, 1999, cycle 236) and Jason-1/2/3 missions. We applied the RADS default state-of-the-art range and geophysical corrections to altimetric data, i.e., the CLS 2D non-parametric SSB, GOT4.8 tide model, etc. Table 1 lists all valid SSB in RADS.

Table 1. SSB corrections available in RADS (the symbol ' $Y$ ' denotes the model is valid in RADS to the specific altimetry mission). The 2D non-parametric SSB correction is the default method in RADS for TOPEX, Jason-1/2/3 altimetry data processing. The codes denote the various SSB corrections in RADS.

\begin{tabular}{ccccc}
\hline SSB (Code in RADS) & $\begin{array}{c}\text { TOPEX } \\
\text { (C011-C343) }\end{array}$ & Jason-1 (C001-C239) & Jason-2 (C001-C303) & Jason-3 (C001-045) \\
\hline $\begin{array}{c}\text { Parametric (1501 [5]) } \\
\text { CLS 2D non-parametric } \\
\quad(1502[8,15])\end{array}$ & $\mathrm{Y}$ & $\mathrm{Y}$ & $\mathrm{Y}$ & $\mathrm{Y}$ \\
$\begin{array}{c}\text { CSR BM4 (1503 [6]) } \\
\text { CLS non-parametric } \\
\quad \text { (MLE3 1512) }\end{array}$ & $\mathrm{Y}$ & & $\mathrm{Y}$ \\
3D non-parametric & & $\mathrm{Y}$ & $\mathrm{Y}$ \\
\hline (1513 [21]) & & $\mathrm{Y}$ & $\mathrm{Y}$ & \\
\hline
\end{tabular}

* Default SSB correction in RADS.

Subsequently, to investigate the long-term trend in SSB and its relations with SWH, we did monthly average of the along-track data and processed the data into $2^{\circ} \times 2^{\circ}$ latitude-longitude cell to account for track density [7]. Then, the monthly data are used to determine the trend using the linear 
least square method. The global mean time series of the parameters are determined by geographically averaging data of each cycle (cosine latitude weighted).

\section{Global mean SSB Evolution Analysis}

Figure 1a shows the global mean SSB time series between 1993 and 2017 in TOPEX, Jason-1/2/3 missions. Comparing BM4 (correction code 1503 in RADS) with parametric SSB correction (1501), obvious differences are observed in TOPEX-B era. The SSB drops remarkably during La Niña event in 1999, which has been emphasized in a previous study [7]. In TOPEX, the change of altimeter from side A to side B in January 1999 was also related to the trend [27]. Besides, note remarkable drops of SSB (to $7 \mathrm{~mm}$, Figure 2a) captured by Jason-2/3 during very strong El Niño event in 2015-2016 (Jason-2 phase A mission ends in 2 October 2016), moderate El Niño event in 2009-2010, and increases in the following La Nina events.

For Jason-1 mission, coherent variations are observed between the two SSB models. The three corrections (CLS 2D non-parametric 1502, CLS non-parametric MLE3 1512 and 3D non-parametric 1513) in Jason-2/3 missions show similar variability but different mean values of the long time series. Furthermore, Jason-3 demonstrates consistent variability in the three SSB corrections with Jason-2 since February 2016 (cycle 001 of Jason-3).

Figure $1 \mathrm{~b}$ shows the time evolution of GMSL with various SSB corrections in Table 1 . The discrepancies among the time series are attribute to SSB in each mission. In RADS, the default SSB is CLS2D non-parametric SSB. There is no obvious bias observed in the combined TOPEX, Jason-1/2/3 SSHA time series (Figure $1 b$, blue curve). The time series with and without SSB correction are shown in Figure 1c, which exhibits trends of $2.89 \pm 0.06 \mathrm{~mm} / \mathrm{yr}$ and $2.96 \pm 0.06 \mathrm{~mm} / \mathrm{yr}( \pm \sigma)$, respectively. The values agree with the GMSL rise trend of $2.9 \mathrm{~mm} / \mathrm{yr}$ from NOAA very well (without Glacial Isostatic Adjustment).

To examine the possible trends in the SSB corrections, we plotted the temporal variations of $2 \mathrm{D}$ and 3D non-parameter SSB corrections with each mission mean removed in Figure 2a,b. In Figure 2, very similar variations are shown from default and alternative SSB corrections. The trend in $2 \mathrm{D}$ non-parameter global mean SSB anomaly (Figure 2a) is not significant from zero $(0.03 \pm 0.03 \mathrm{~mm} / \mathrm{yr})$ while significant trends of $-1.27 \pm 0.21 \mathrm{~mm} / \mathrm{yr},-0.61 \pm 0.57 \mathrm{~mm} / \mathrm{yr}$ and $-0.26 \pm 0.13 \mathrm{~mm} / \mathrm{yr}$ appear in TOPEX-A, TOPEX-B and Jason-2 SSB corrections. Alternatively, the BM4 and 3D non-parameter SSBs exhibit consistent rates in the same time period (1993-2016, Figure 2b). Hence, the trends in SSB may affect the determined GMSL trends in the according periods.

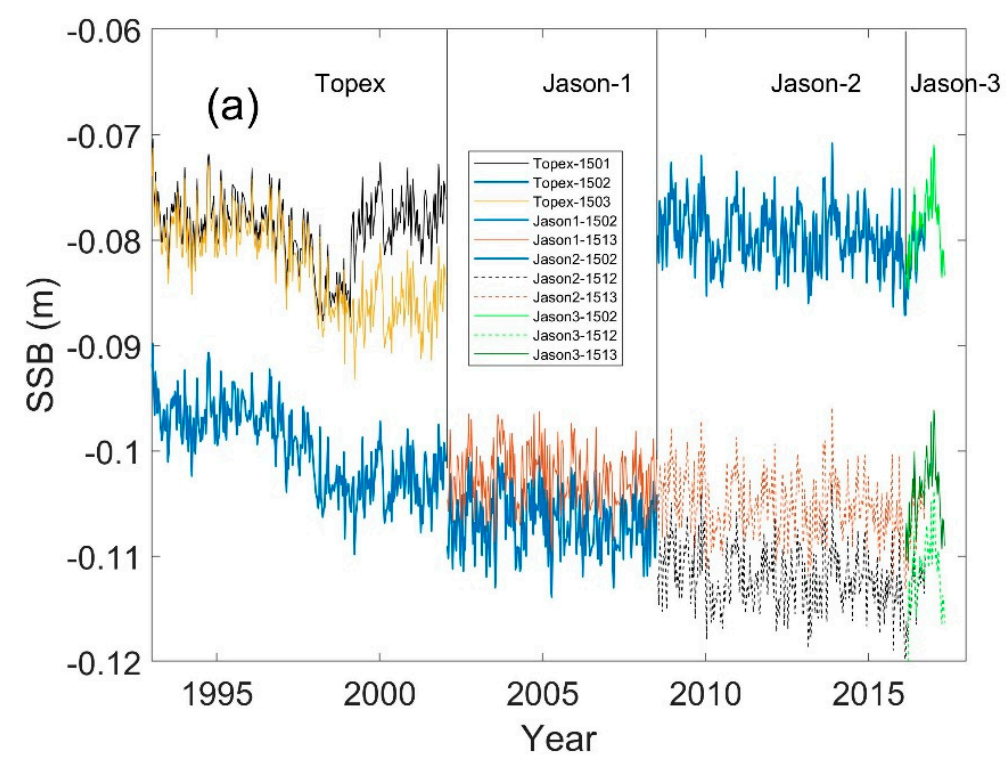

Figure 1. Cont. 

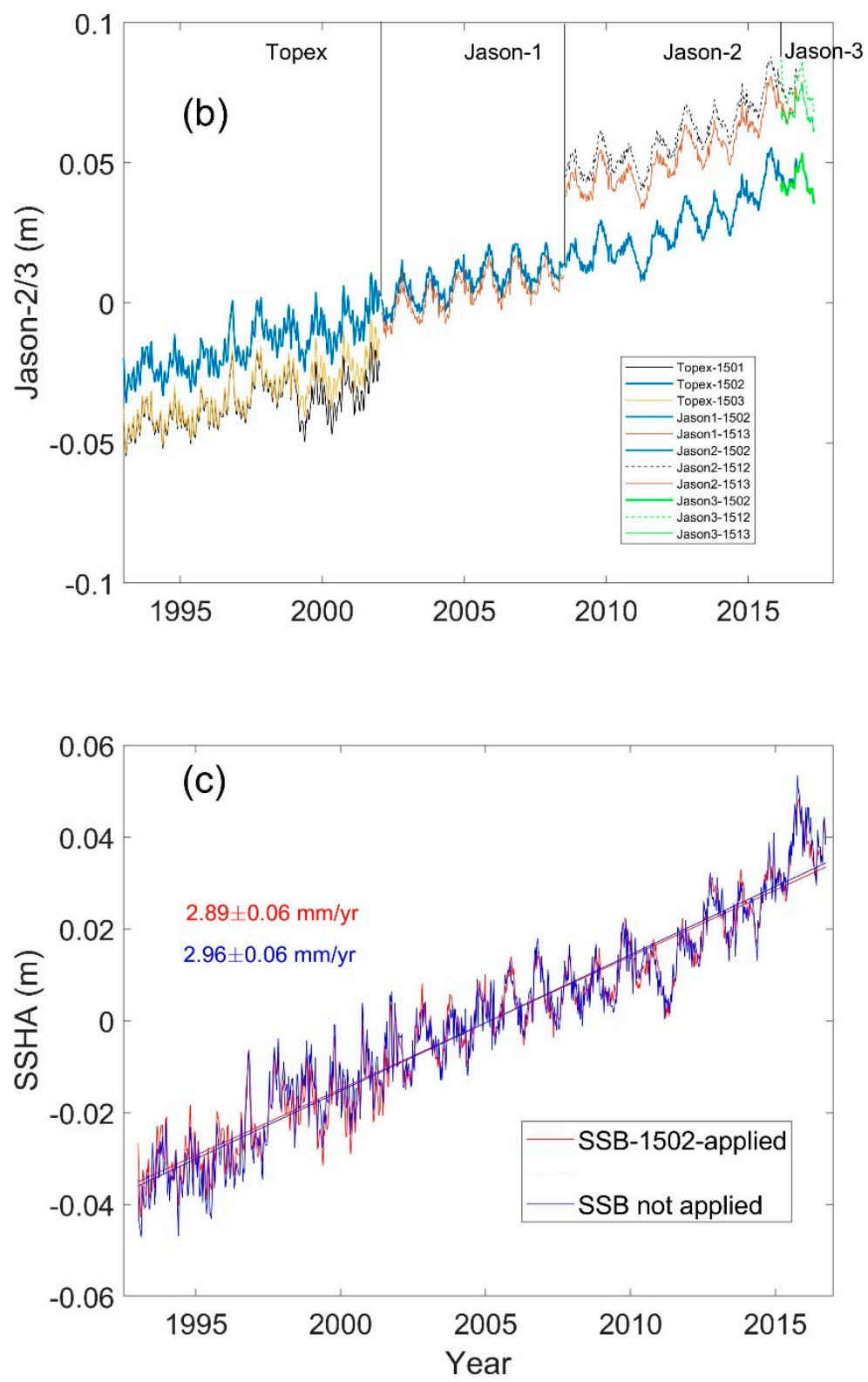

Figure 1. (a) Time evolution of cycle averaged SSB corrections (m) applied to TOPEX, Jason-1/2/3 missions. (b) SSHA (m) time series with various SSB corrections shown in (a). (c) SSHA (m) time series with and without operational 2D non-parametric SSB correction. Refer Table 1 for the codes in the legend of $(\mathbf{a}, \mathbf{b})$. For each cycle, the values were weighted by cosine latitude. 


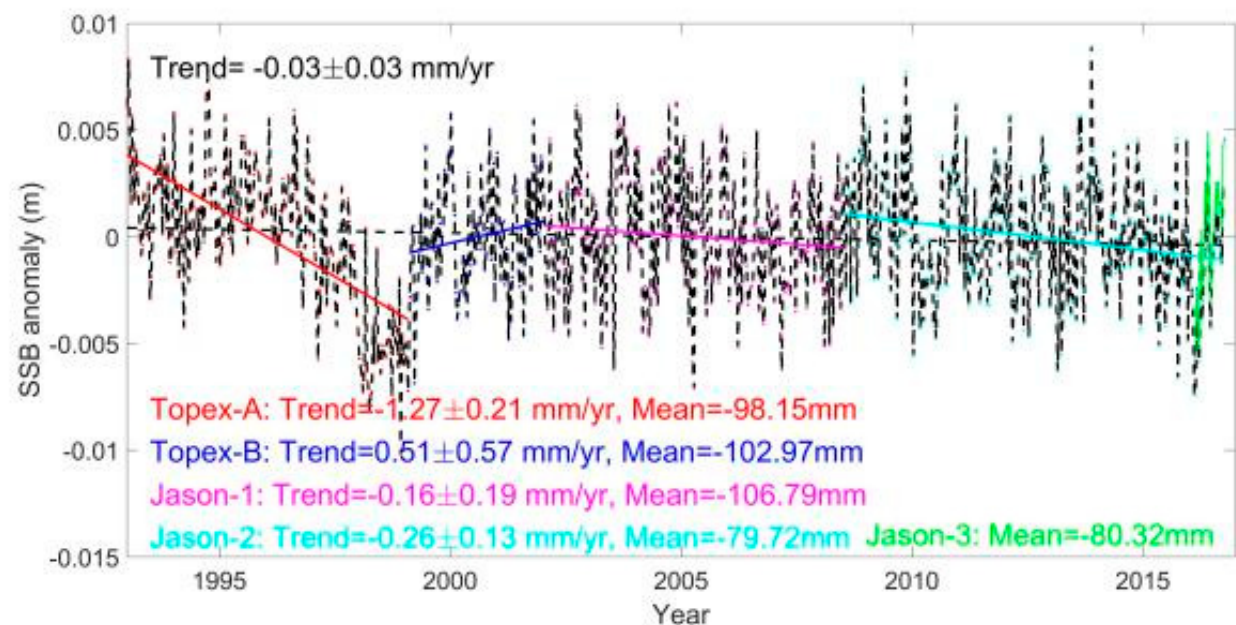

(a)

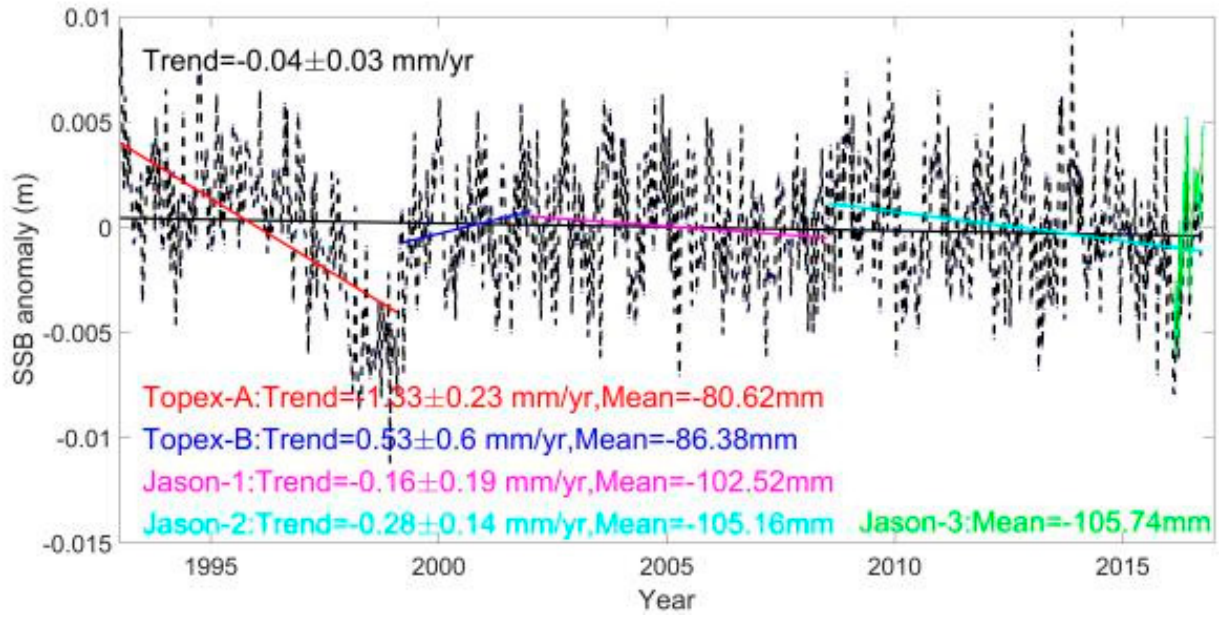

(b)

Figure 2. Time series of cycle averaged SSB anomaly (m, weighted by cosine latitude) computed from (a) 2D non-parameter correction (1502), (b) BM4 (TOEPX) and 3D non-parameter SSB corrections (Jason-1/2/3). The mean in each mission is removed.

\section{Spatial Pattern of SSB Trend}

Considering the remarkable trends in TOPEX mission, we present the spatial pattern of SSB trend after the 2D non-parametric SSB correction in Figure 3a (TOPEX-A, 1993.01-1998.12), Figure 3c (TOPEX-B, 1999.02-2001.12), Figure 3e (Jason-1) and Figure 3g (Jason-2). In TOPEX-A, obvious negative trends are shown in Southern Pacific Ocean, which means that the correction decreases the 'real' spatial trend from the altimetry data in the regions [18-20].

Compared with Figure 3a, the trend in TOPEX-B era (Figure 3c) is larger with positive patterns in the southern oceans and along the equator. In Jason-1 mission (Figure 3e), high positive and negative trends are observed in e.g., Western/tropical Pacific, South of Australia, Gulf of Alaska and southwest of South America. In Jason-2 era, the patterns (Figure 3g) are almost reversed with positive trends presented in Gulf Stream and the trend in Gulf of Alaska disappeared.

Figure $3 b, d, f, h$ denote the differences of trends between alternative SSB corrections (e.g., parametric for TOPEX, 3D non-parametric for Jason) and the default one. In TOPEX-A (Figure 3b), the discrepancies are mainly presented in the regions with high SWH (e.g., Southern Ocean and Gulf of Alaska). In the northern Atlantic Ocean and along the equator of east Pacific, the alternative correction exhibits higher trend than the default SSB. In Figure 3d, the changes of trends are observed in Pacific and Atlantic 
Oceans and along the equator of east Pacific. The 3D non-parametric correction shows similar spatial patterns as the default SSB in Jason-1/2 missions, but a slightly decreased (Figure 3f) or increased trend (Figure 3h).
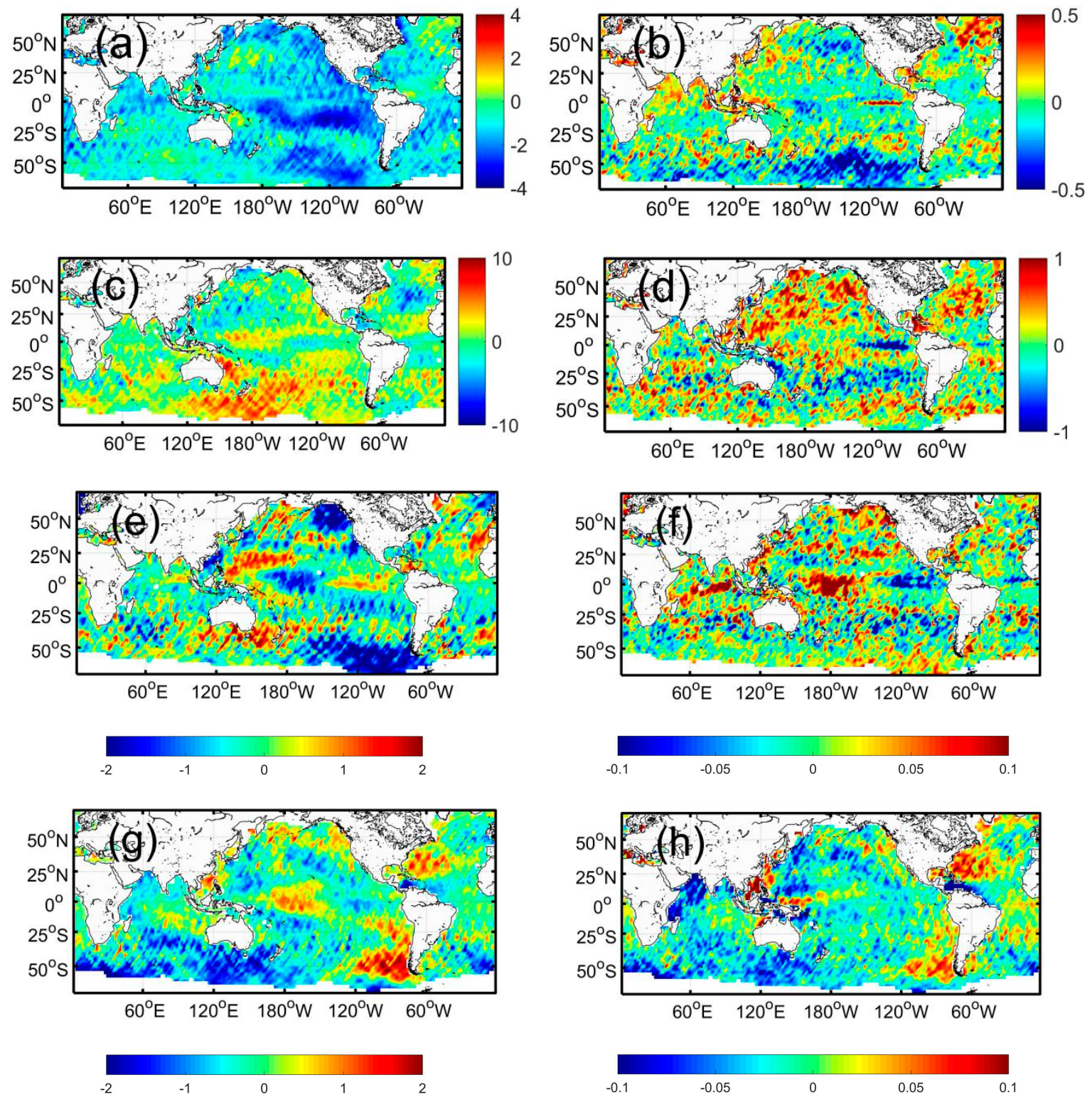

Figure 3. (Left panels) Spatial pattern of 2D non-parametric SSB correction trend (mm/yr) in (a) TOPEX-A, (c) TOPEX-B, (e) Jason-1 and (g) Jason-2 missions. (Right panels) The difference between parametric (b), 3D non-parametric $(\mathbf{d}, \mathbf{f}, \mathbf{h})$ and 2D non-parametric SSB correction trends.

\section{Zonal SWH and SSB Trends}

Compared with the wind speed, SWH affects SSB even more. To further illustrate the correlation between two parameters, we show the variation of spatial coherency between 2D nonparametric SSB trend and SWH trend along the latitude in Figure 4. The Jason-1/2 missions demonstrate stronger and more stable coherency with SWH than TOPEX. For each altimetry mission, lower spatial coherency patterns are found in the tropical regions $\left(20^{\circ} \mathrm{S}-20^{\circ} \mathrm{N}\right)$. The dynamic processes are the main contributors to the SSH changes over the regions and caused lower coherency over the regions in TOPEX era. Note that the highest coherency $(\leq-0.95)$ appears from Jason- $1 / 2$ mission, especially outside $\pm 30^{\circ}$ parallels. 
However, the coherency decreases in TOPEX missions, which implies that the SSB trend is not only dependent on the SWH trend over the regions.

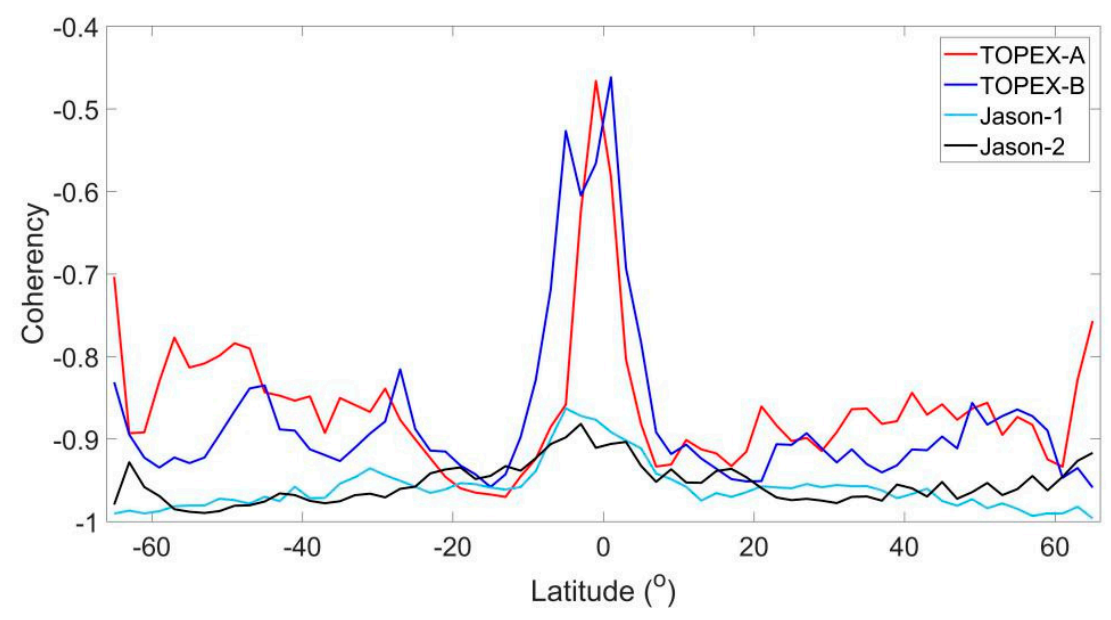

Figure 4. The variation of spatial coherency between 2D nonparametric trend and SWH trend from TOPEX-A, TOPEX-B, Jason-1 and Jason-2 missions.

Moreover, Figure 5 presents the variations of zonally averaged 2D nonparametric SSB and SWH trends from various altimetry missions, which have been weighted by the cosine latitude. The zonally averaged SWH trends are multiplied by a factor -0.03 . In terms of Jason- $1 / 2$ missions, the zonally averaged SSB trend is coherent to SWH trend along the latitude except at $10^{\circ} \mathrm{S}-30^{\circ} \mathrm{N}$ due to the dynamic progress over the regions. Compared with the results from Jason- $1 / 2$ mission, dramatic differences between zonally averaged SSB trend and $(-0.03 \times \mathrm{SWH})$ trend are found from TOPEX-A mission. TOPEX-B shows a temporal variation quite different from the other missions but high discrepancies are also clearly seen in tropical regions $\left(20^{\circ} \mathrm{S}-20^{\circ} \mathrm{N}\right)$. Consequently, unlike that from Jason- $1 / 2 \mathrm{mission}$, the SSB trend does not depend on SWH in TOPEX mission.

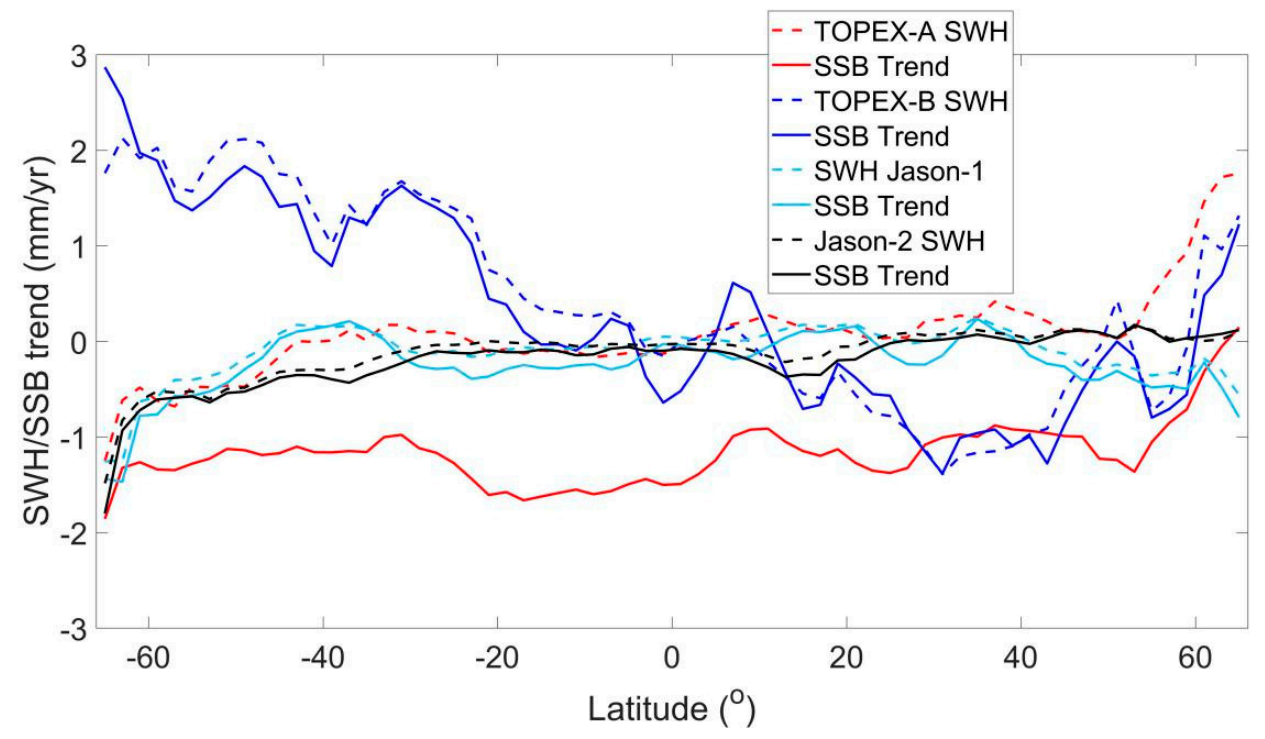

Figure 5. The variation of zonally averaged 2D nonparametric SSB and SWH $\times(-0.03)$ trend $(\mathrm{mm} / \mathrm{yr})$ from TOPEX-A, TOPEX-B, Jason-1 and Jason-2 missions.

\section{Discussion and Conclusions}

It is still unclear to what extent SSB depends on errors in parameter estimations or to the wave physics. The wave periods measured by altimeters are generally shifted from that measured by surface 
buoys due to different cut-off frequencies [25], which could result in a discrepancy between wave models such as WAVEWATCH III and ERA-Interim. The inaccuracy of numerical wave model outputs and wind fields may cause inaccurate theoretical modelling of SSB, especially in tropical regions. On the other hand, poor SWH estimation in TOPEX retracking due to poor downlinked waveform data, and instrumental differences (e.g., footprint sizes) between TOPEX and Jason altimeters could be responsible for the SSB differences in the missions. To correct for the physical effects of the interaction between the radar signal and the waves, it is necessary to work on a retracked dataset that is free from the retracker-related SSB noise [24].

Watson et al. [26] pointed out that TOPEX-A data may have an instrumental drift of $0.9 \pm 0.5 \mathrm{~mm} / \mathrm{yr}$ to $\sim 1.5 \pm 0.5 \mathrm{~mm} / \mathrm{yr}$ over 1993-1998 depending on the vertical land motion correction applied to the tide gauges. Very recently, Dieng et al. [27] quantified this value as $1.5 \pm 0.5 \mathrm{~mm} / \mathrm{yr}$ by using the budget approach which lead to closure of the sea level budget. Beckley et al. [28] mentioned that TOPEX altimeter data had a $1 \mathrm{~mm} / \mathrm{yr}$ drift. In this study, we examined the variability of SSB corrections in over 24 years and its contribution to the global mean sea level change rate. In TOPEX-A mission, the global averaged SSB correction demonstrates a significant trend of $-1.3 \pm 0.2 \mathrm{~mm} / \mathrm{yr}$.

Figure 6 shows the spatial pattern of the 2D non-parametric SSB trend over the time period 1993-2016. Negative trend is up to $-0.15 \mathrm{~mm} / \mathrm{yr}$ in the Southern Ocean and Gulf of Alaska, where higher SWHs are observed. In other regions, the trend is neglectable. In Figure 7, the zonal averaged SSB trend is compared with zonal averaged SLA trend $\left(2^{\circ}\right)$ and NOAA released SLA trend $\left(0.5^{\circ}\right)$. The SSB trend is around $-0.03 \mathrm{~mm} / \mathrm{yr}$ north of $50^{\circ} \mathrm{S}$ parallel (i.e., $1 \%$ of current global sea level rise rate). However, it accounts for a zonal averaged sea level trend of about $4 \%$ and $2 \%$ near $60^{\circ} \mathrm{S}$ and $50^{\circ} \mathrm{N}$, respectively.

In summary, the trends in SSB corrections are considerable in TOPEX and Jason-2 missions, but their contribution to the long term GMSL trend is not significant. The significant discrepancy of the spatial coherency between SWH and SSB trend is present in TOPEX sides A and B missions, which needs to be further studied in the future [28]. The variation of the spatial coherency along the latitude shows that the SSB trend in tropical regions is less sensitive to the SWH trend in Jason-1/2 missions. Moreover, the ENSO activities may also contribute to the temporal variability of global mean SSB correction.

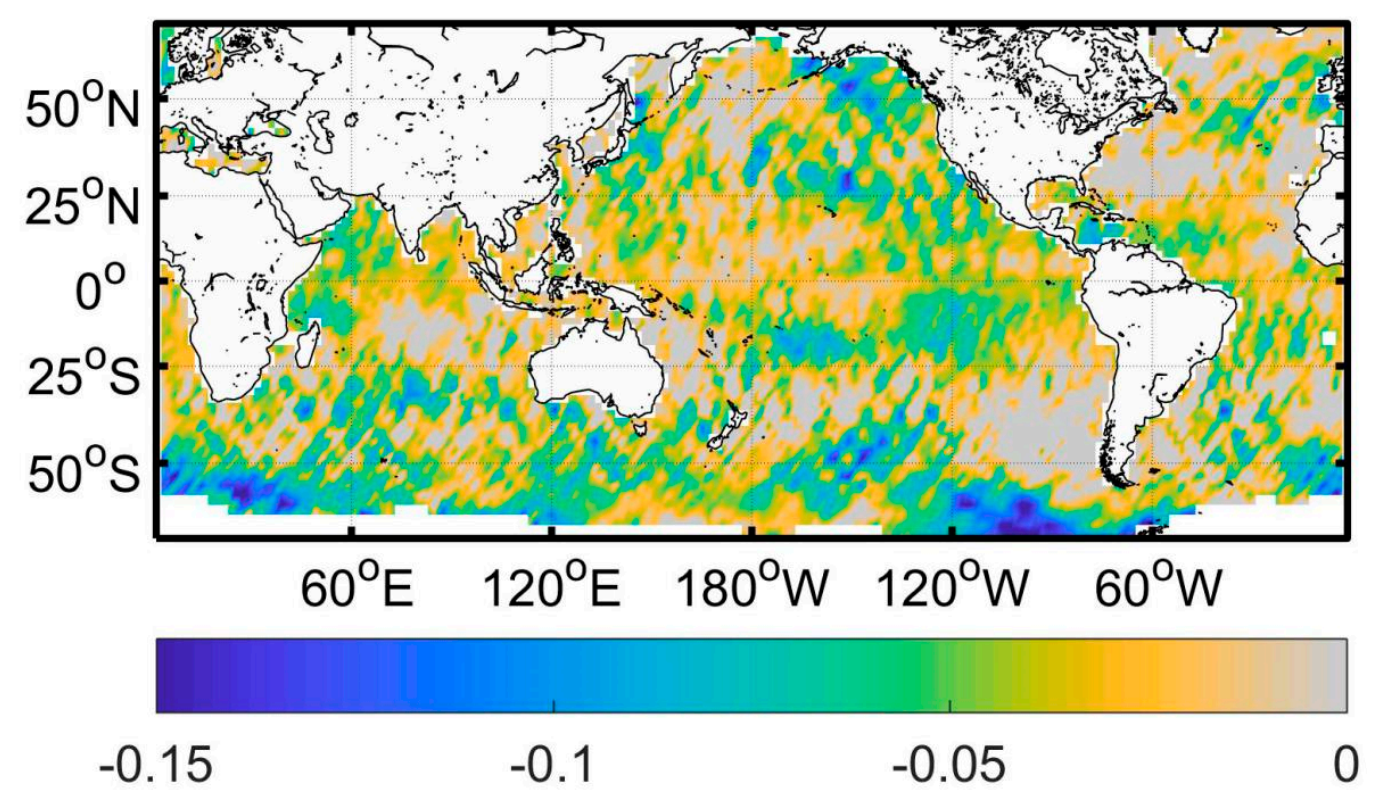

Figure 6. Spatial pattern of 2D non-parametric SSB correction trend (mm/yr, 1993-2016) in multiple altimetry missions. 


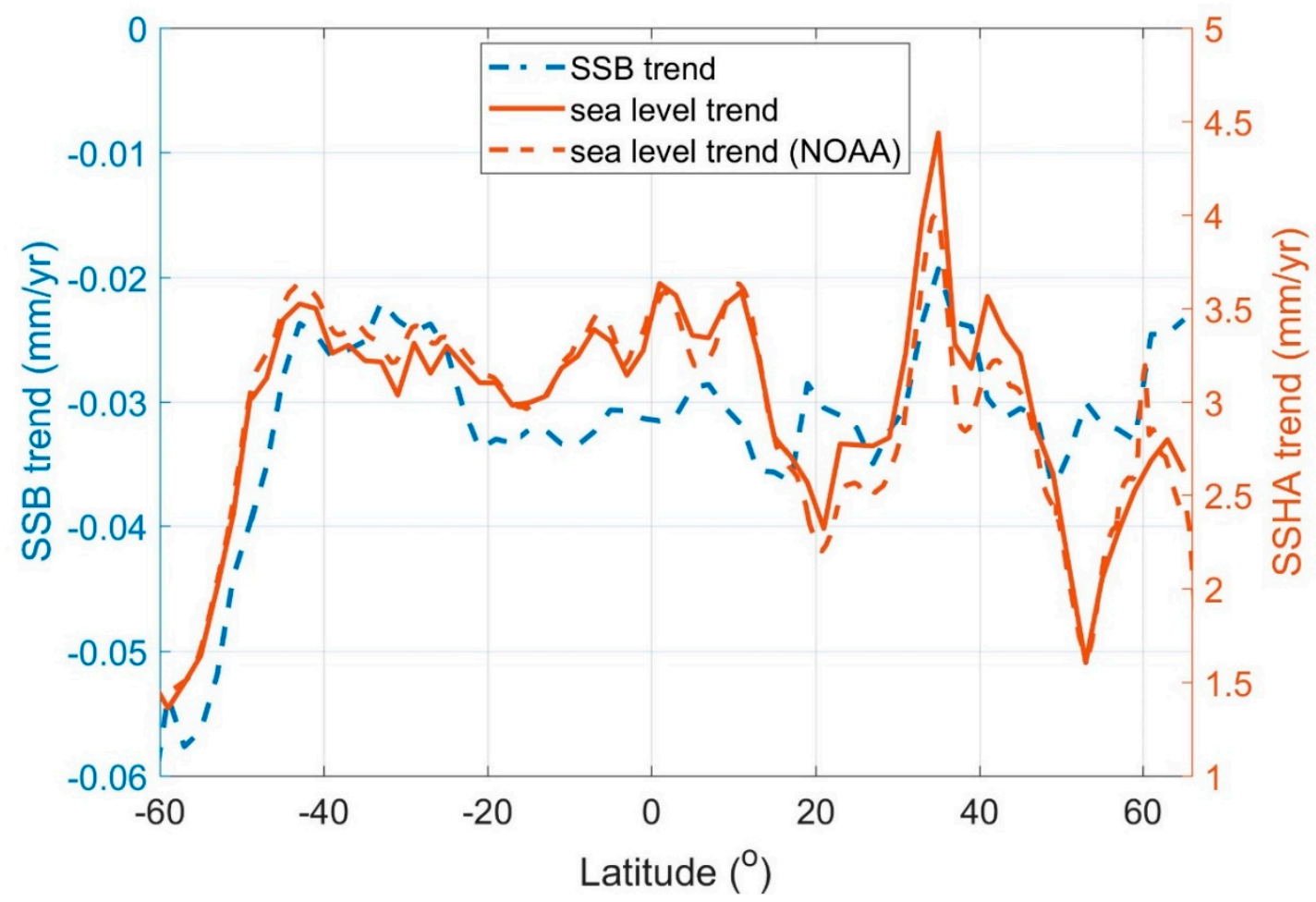

Figure 7. The variation of zonally averaged CLS nonparametric SSB trend (mm/yr) from TOPEX-A, TOPEX-B, Jason-1 and Jason-2 missions.

Author Contributions: Y.C. and Q.X. conceived the original idea and wrote the manuscript. Under the supervision of X.L., Y.C. carried out data analysis and prepared all of the figures. Q.X., L.G. and X.L. helped to improve the results and revised the paper. B.Z. and T.L. provided comments and valuable suggestions on the paper. All authors read and approved the final version of the manuscript.

Funding: This study was supported by the Guangdong Special Fund Program for Marine Economy Development (Grant No. GDME-2018B001), Dayu Scholar Program (for Q. X.), the CAS (Chinese Academy of Sciences) "100 Talent" Program (grant Y9KY04101L), the National Natural Science Foundation for Young Scientists of China (Grant No. 41606200), the National Key R\&D Program of China (Grant No. 2016YFC1401008).

Acknowledgments: The authors thank the editor and three anonymous reviewers for their constructive comments which help to improve the paper. The global sea level trend and map are provided by NOAA/NESDIS/STAR Laboratory for Satellite Altimetry and available online at https://www.star.nesdis.noaa.gov/.

Conflicts of Interest: The authors declare no conflict of interest.

\section{References}

1. Ablain, M.; Cazenave, A.; Larnicol, G.; Balmaseda, M.; Cipollini, P.; Faugère, Y.; Fernandes, M.; Henry, O.; Johannessen, J.; Knudsen, P. Improved sea level record over the satellite altimetry era (1993-2010) from the climate change initiative project. Ocean Sci. 2015, 11, 67-82. [CrossRef]

2. Ablain, M.; Legeais, J.F.; Prandi, P.; Marcos, M.; Fenoglio-Marc, L.; Dieng, H.B.; Benveniste, J.; Cazenave, A. Satellite altimetry-based sea level at global and regional scales. Surv. Geophys. 2017, 38, 7-31. [CrossRef]

3. Nerem, R.; Chambers, D.; Choe, C.; Mitchum, G. Estimating mean sea level change from the topex and jason altimeter missions. Mar. Geod. 2010, 33, 435-446. [CrossRef]

4. Masters, D.; Nerem, R.; Choe, C.; Leuliette, E.; Beckley, B.; White, N.; Ablain, M. Comparison of global mean sea level time series from topex/poseidon, jason-1, and jason-2. Mar. Geod. 2012, 35, 20-41. [CrossRef]

5. Gaspar, P.; Ogor, F.; Le Traon, P.Y.; Zanife, O.Z. Estimating the sea state bias of the topex and poseidon altimeters from crossover differences. J. Geophys. Res. Ocean. 1994, 99, 24981-24994. [CrossRef]

6. Chambers, D.P.; Hayes, S.A.; Ries, J.C.; Urban, T.J. New topex sea state bias models and their effect on global mean sea level. J. Geophys. Res. Ocean. 2003, 108. [CrossRef] 
7. Ablain, M.; Cazenave, A.; Valladeau, G.; Guinehut, S. A new assessment of the error budget of global mean sea level rate estimated by satellite altimetry over 1993-2008. Ocean Sci. 2009, 5, 193-201. [CrossRef]

8. Labroue, S.; Gaspar, P.; Dorandeu, J.; Zanife, O.; Mertz, F.; Vincent, P.; Choquet, D. Nonparametric estimates of the sea state bias for the jason-1 radar altimeter. Mar. Geod. 2004, 27, 453-481. [CrossRef]

9. Tran, N.; Labroue, S.; Philipps, S.; Bronner, E.; Picot, N. Overview and update of the sea state bias corrections for the jason-2, jason-1 and topex missions. Mar. Geod. 2010, 33, 348-362. [CrossRef]

10. Chelton, D.B. The sea state bias in altimeter estimates of sea level from collinear analysis of topex data. J. Geophys. Res. Ocean. 1994, 99, 24995-25008. [CrossRef]

11. Vandemark, D.; Tran, N.; Beckley, B.; Chapron, B.; Gaspar, P. Direct estimation of sea state impacts on radar altimeter sea level measurements. Geophys. Res. Lett. 2002, 29, 1-1-1-4. [CrossRef]

12. Chapron, B.; Vandemark, D.; Elfouhaily, T.; Thompson, D.; Gaspar, P.; Labroue, S. Altimeter sea state bias: A new look at global range error estimates. Geophys. Res. Lett. 2001, 28, 3947-3950. [CrossRef]

13. Gaspar, P.; Florens, J.P. Estimation of the sea state bias in radar altimeter measurements of sea level: Results from a new nonparametric method. J. Geophys. Res. Ocean. 1998, 103, 15803-15814. [CrossRef]

14. Feng, H.; Yao, S.; Li, L.; Tran, N.; Vandemark, D.; Labroue, S. Spline-based nonparametric estimation of the altimeter sea-state bias correction. IEEE Geosci. Remote Sens. Lett. 2010, 7, 577-581. [CrossRef]

15. Gaspar, P.; Labroue, S.; Ogor, F.; Lafitte, G.; Marchal, L.; Rafanel, M. Improving nonparametric estimates of the sea state bias in radar altimeter measurements of sea level. J. Atmos. Ocean. Technol. 2002, 19, 1690-1707. [CrossRef]

16. Fu, L.L.; Glazman, R. The effect of the degree of wave development on the sea state bias in radar altimetry measurement. J. Geophys. Res. Ocean. 1991, 96, 829-834. [CrossRef]

17. Glazman, R.; Fabrikant, A.; Srokosz, M. Numerical analysis of the sea state bias for satellite altimetry. J. Geophys. Res. Ocean. 1996, 101, 3789-3799. [CrossRef]

18. Andersen, O.B.; Cheng, Y. Long term changes of altimeter range and geophysical corrections at altimetry calibration sites. Adv. Space Res. 2013, 51, 1468-1477. [CrossRef]

19. Cheng, Y.; Andersen, O.B. Impacts of altimeter corrections on local linear sea level trends around taiwan. Int. J. Remote Sens. 2013, 34, 6738-6748. [CrossRef]

20. Cheng, Y.; Xu, Q.; Andersen, O.B. Sea-level trend in the south china sea observed from 20 years of along-track satellite altimetric data. Int. J. Remote Sens. 2014, 35, 4329-4339. [CrossRef]

21. Tran, N.; Vandemark, D.; Labroue, S.; Feng, H.; Chapron, B.; Tolman, H.; Lambin, J.; Picot, N. Sea state bias in altimeter sea level estimates determined by combining wave model and satellite data. J. Geophys. Res. Ocean. 2010, 115. [CrossRef]

22. Pires, N.; Fernandes, M.; Gommenginger, C.; Scharroo, R. A conceptually simple modeling approach for jason-1 sea state bias correction based on 3 parameters exclusively derived from altimetric information. Remote Sens. 2016, 8, 576. [CrossRef]

23. Jiang, M.F.; Xu, K.; Liu, Y.L.; Wang, L. Estimating the sea state bias of jason-2 altimeter from crossover differences by using a three-dimensional nonparametric model. IEEE J. Sel. Top. Appl. Earth Obs. Remote Sens. 2016, 9, 5023-5043. [CrossRef]

24. Passaro, M.; Nadzir, Z.A.; Quartly, G.D. Improving the precision of sea level data from satellite altimetry with high-frequency and regional sea state bias corrections. Remote Sens. Environ. 2018, 218, 245-254. [CrossRef]

25. Wang, X.; Ichikawa, K. Effect of High-Frequency Sea Waves on Wave Period Retrieval from Radar Altimeter and Buoy Data. Remote Sens. 2016, 8, 764. [CrossRef]

26. Watson, C.S.; White, N.J.; Church, J.A.; King, M.A.; Burgette, R.J.; Legresy, B. Unabated global mean sea-level rise over the satellite altimeter era. Nat. Clim. Chang. 2015, 5, 565. [CrossRef]

27. Dieng, H.B.; Cazenave, A.; Meyssignac, B.; Ablain, M. New estimate of the current rate of sea level rise from a sea level budget approach. Geophys. Res. Lett. 2017, 44, 3744-3751. [CrossRef]

28. Beckley, B.D.; Callahan, P.S.; Hancock, D.W.; Mitchum, G.T.; Ray, R.D. On the "cal-mode" correction to topex satellite altimetry and its effect on the global mean sea level time series. J. Geophys. Res. Ocean. 2017, 122, 8371-8384. [CrossRef]

(C) 2019 by the authors. Licensee MDPI, Basel, Switzerland. This article is an open access article distributed under the terms and conditions of the Creative Commons Attribution (CC BY) license (http://creativecommons.org/licenses/by/4.0/). 